\title{
Treatment of early onset schizophrenia: recent trends, challenges and future considerations
}

\section{Nora S. Vyas* and Nitin Gogtay}

Child Psychiatry Branch, National Institute of Mental Health, National Institutes of Health, Bethesda, MD, USA

\section{Edited by:}

Hanna E. Stevens, Yale University, USA

\section{Reviewed by:}

Magdalena Romanowicz, Stanford University, USA

Jon Carlson, Yale University, USA

*Correspondence:

Nora S. Vyas, Child Psychiatry Branch, National Institute of Mental Health, National Institutes of Health, Building 10, Room 3N202, Center Drive, Bethesda, MD 20892-1600, USA e-mail: nora.vyas@nih.gov
Early onset schizophrenia (onset before adulthood) is a rare, severe, and chronic form of schizophrenia. The clinical presentation of schizophrenia at this unusually early age of onset has been associated with premorbid developmental abnormalities, poor response to neuroleptic treatment, greater admission rates, and poor prognosis. This is a brief, condensed review of current treatment strategies for the early onset population highlighting the need for novel treatment strategies for these generally treatment-refractory cases. Based on the current literature, second-generation antipsychotics remain the mainstay of treatment, although current medications provide suboptimal response at best. Based on the adult literature, combining antipsychotic treatment with psychotherapeutic intervention may be a more comprehensive treatment strategy. Indeed, early detection, identification of relevant biomarkers, coupled with advancing knowledge of the neurochemical and neuroanatomic pathways may help design informed and novel treatment strategies.
Schizophrenia is a complex psychiatric disorder afflicting $1 \%$ of the population worldwide. The neurodevelopmental model of schizophrenia posits that the pathophysiology can be traced in the early stages of development (Weinberger, 1987; Rapoport et al., 1997; Gogtay et al., 2011). Adolescent onset schizophrenia is less common and phenotypically more severe. The very early onset form of this debilitating disorder (childhood onset schizophrenia; onset of psychosis before age 13) is exceedingly rare, much more severe, may be homogeneous, with a chronic, treatment-refractory course (Childs and Scriver, 1986; Sporn et al., 2007). For this review, both are jointly referred to as early onset schizophrenia (EOS). The early forms are both phenotypically and neurobiologically continuous with the adult-onset illness (Jacobsen and Rapoport, 1998; Hollis, 2000), though EOS patients show greater neurodevelopmental impairments early in life such as delay in language/speech, linguistic ability, motor coordination, and poor psychosocial functioning (Asarnow et al., 1994; Caplan, 1994; Nicolson and Rapoport, 1999; Nicolson et al., 2000; McClellan and Werry, 2001; McClellan et al., 2003; Fleischhaker et al., 2005; Gornick et al., 2005; Vyas et al., 2007).

The clinical severity and early age at onset in EOS results in long-term use of antipsychotic medication as a mainstay of treatment, coupled with psychotherapeutic intervention. Increasingly, efforts are being made toward early detection and management of prodromal symptoms, which may make it possible to implement early preventative and treatment strategies before the onset of the syndromal illness. The use of medication (or treatment in general) at the prodromal stage, however, has also resulted in challenging clinical and ethical issues. Therefore, the identification of novel and evidence-based treatment interventions that effectively improve symptomatology and outcome in EOS is warranted. We discuss issues relating to prodromal intervention, followed by a selective review on pharmacological treatment and psychotherapeutic interventions mostly focusing on EOS. It is assumed that both treatment modalities are part of a comprehensive treatment plan, involving an initial assessment of the patient, awareness of the child's developmental stage, and understanding of the family system perspective.

\section{EARLY DETECTION AND MANAGEMENT OF PSYCHOSIS}

Adolescence is a period of profound changes in the brain structure with a complex interplay between biological, psychological, and social factors. Mental health problems commonly emerge in adolescence and many adolescents have enduring disorders rather than simply a transient "teenage" emotional turmoil. Individuals who develop psychosis often experience a prodromal phase (also known as "at-risk mental state"), which typically involves changes in perception, behavior, cognition, mood, and physiology (Yung and McGorry, 1996, McGorry et al., 2001). This phase is ambiguous because of the non-specificity of symptoms that are commonly observed during development in adolescence, and the low predictive power in identifying individuals who make a transition to psychosis (McGorry and Killackey, 2002). Structured instruments, such as Structured Interview for Prodromal Syndromes (SIPS; McGlashan et al., 2001), Scale of Prodromal Symptoms (SOPS; Miller et al., 1999), the Bonn Scale for the Assessment of Basic Symptoms (BSABS; Gross et al., 1987), the Personal Assessment and Crisis Evaluation (PACE; Phillips et al., 2002), and the Comprehensive Assessment of At Risk Mental States (CAARMS; Yung et al., 2004), can help better characterize the prodromal phase although these lack "predictive" value. In recent years, better characterization of the prodrome phase of the disorder and improved prediction algorithms have shown to be effective in informing the timing and management process of early intervention (Cadenhead et al., 2010). In the PACE study, Yung et al. (2004) conducted a 12month follow-up on individuals with ultra high-risk, proposing 
a "four-or-more" algorithm for risk identification, including poor functioning, long duration of symptoms, high levels of depression, and reduced attention. The algorithm showed a positive predictive value of $80 \%$, with heightened specificity and sensitivity values (Yung et al., 2004). In the North American Prodrome Longitudinal Study (NAPLS) cohort, Cannon et al. (2008) followed up 291 treatment-seeking patients with prodromal symptoms at regular intervals for up to 2.5 years. The study showed conversion rates to be $35 \%$ at follow-up, with baseline characteristics predictive of psychosis to include a genetic predisposition of schizophrenia alongside reduced overall functioning, heightened levels of abnormal thought content, greater psychosocial impairment, and a history of substance abuse (Cannon et al., 2008). Similar findings have been reported in the European Prediction of Psychosis (EPOS) study (Ruhrmann et al., 2010). However, there is a paucity of "biomarkers" for this phase with good predictive value either for course or treatment response. Although the identification of biomarkers for schizophrenia is in its early stages, some attempts have been made to discover biomarkers in EOS (Taurines et al., 2010; Micó et al., 2011). There is limited evidence that management and symptom specific treatment of help-seeking prodromal patients may delay or prevent the onset of psychosis; however the uncertainty of course prediction adds to the risk of stigmatization and heightened anxiety in individuals and their families. Additionally, the EOS cases tend to be insidious, non-episodic, and typically result in rapid deterioration; providing a limited chance to study and intervene during this window.

The identification of biomarkers would improve the ability to intervene during the prodromal period or earlier. The search for clinically relevant biomarkers is a challenging task in a heterogeneous disorder like schizophrenia but studying EOS provides a unique opportunity as the phenotype is relatively homogenous, associated with less risk of secondary influences from disease associated alterations of environment (e.g., marijuana, smoking, hospital admissions, etc.) and typically shows more salient genetic loading (Vyas et al., 2010, 2011a). Adult studies have attempted to identify putative biomarkers. For example, a neurocognitive deficits in schizophrenia is considered a core feature of the illness (meta-analysis, Heinrichs and Zakzanis, 1998; Heaton et al., 2001; Keefe and Fenton, 2007) and studies on ultra high-risk cohorts suggest that impairments in olfactory identification and spatial working memory (measures targeting the dorsolateral prefrontal cortex and cortical physiological processes), may have a strong predictive value for conversion to psychosis (Brewer et al., 2006). Neurophysiological measures such as electroencephalography, event-related potentials, prepulse inhibition, and mismatch negativity, also show promise as potential biomarkers (Javitt et al., 2008; Wiedemann, 2011; Vyas et al., 2012) but further work to elucidate the relationship of such measures with specific clinical expression (e.g., negative symptoms, cognitive functioning) is needed. Neuroimaging studies have shown relatively less predictive value despite consistent reports of progressive structural brain abnormalities associated with schizophrenia (Gogtay et al., 2004; Rapoport and Gogtay, 2011), and non-psychotic siblings of COS patients (Gogtay et al., 2003; Greenstein et al., 2011). Some studies have suggested that high-risk individuals that go on to become psychotic show less gray matter volume in the right medial temporal, lateral temporal, inferior frontal cortex, and in the cingulate cortex bilaterally, while individuals who do not develop psychosis show changes restricted to the cerebellum (Pantelis et al., 2003). Such observations should be strengthened further with multimodal neuroimaging.

\section{PHARMACOLOGICAL TREATMENT IN EOS}

There is a relative dearth of evidence-based studies of antipsychotic (both typical and atypical) efficacy in EOS, partly because of the rarity of the population and partly because it is difficult to do treatment trials in children with severe illness (Gogtay and Rapoport, 2008). Taken together, these studies suggest that although first-generation antipsychotics (FGAs) improve positive symptomatology, they elicit significant extra pyramidal side effects, tardive dyskinesia, and prolactin elevations (Pool et al., 1976; Realmuto et al., 1984; Spencer et al., 1992; Findling et al., 1998). As a result, second-generation antipsychotics (SGA, or atypical antipsychotics) have become the mainstay of therapy in the treatment of EOS, because of their potential for lower propensity to induce extrapyramidal symptoms and reduced risk of tardive dyskinesia (Madaan et al., 2008; Masi and Liboni, 2011). However the Cochrane review identified 6 (clinical trials) studies with a total of 256 children and adolescents, to examine the effects of antipsychotic medication for EOS (Kennedy et al., 2007). The SGA used for comparisons were clozapine, risperidone, and olanzapine. The authors concluded that there was limited data that supported one antipsychotic medication over another for the treatment of EOS. There was no superiority of SGAs over FGAs, given the evidence showing small differences in effect size for alleviating positive and negative symptoms. Furthermore, an 8-week, government-funded, randomized double-blind trial on EOS entitled "Treatment of Early-Onset Schizophrenia Spectrum" (TEOSS) showed that SGAs, risperidone and olanzapine, were not superior to FGA, molindone, in symptom improvement. Risperidone and olanzapine were associated with high degrees of weight gain (risperidone additionally showed elevated prolactin concentration) in comparison with molindone, while individuals prescribed to molindone showed akathisia (Sikich et al., 2008).

Clozapine remains the gold standard treatment for schizophrenia, and has been shown to have a more favorable profile of clinical response compared with haloperidol and olanzapine in treatmentrefractory EOS (Spencer et al., 1992; Mozes et al., 1994; Towbin et al., 1994; Kumra et al., 1996, 2008; McEvoy et al., 2006). However, clozapine remains as the last resort choice limited by its significant side effect profile on the hematopoietic system (agranulocytosis), cardiovascular system (myocarditis), central nervous system (seizures, akinesia, myoclonic jerks), and liver function, along with other side effects such as severe movement disorders, hypersalivation, hyperglycemia, diabetes, and weight gain, which are particularly problematic for children and young adults (Connor et al., 2001; Vyas et al., 2011b).

Clearly, there is an ongoing debate about the efficacy of atypical medications accounting for the long-term side effects profile, and therefore there is a pressing need for larger randomized control trials (RCTs), to delineate the best available antipsychotic agents, and provide a platform for novel drug discovery. 


\section{PSYCHOTHERAPEUTIC INTERVENTIONS}

To date, there are no published RCTs of psychosocial treatments for children with schizophrenia. However, the adult literature has supported adjunct psychosocial and individualized psychological treatments (Eack et al., 2009; review, Vyas et al., 2012). A review concluded that psychosocial therapies (cognitive behavioral therapy, CBT), family intervention, social skills training, and cognitive remediation) are effective adjuncts to pharmacological interventions in adults with schizophrenia (McGurk et al., 2007; Patterson and Leewenkamp, 2008). For example, CBT addresses dysfunctional beliefs, coping strategies, "tuning" of cognitive abilities, and behavior modification, by linking and then re-evaluating thoughts and feelings about the presentation of clinical symptoms, which in turn aims to improve the mental states of patients. Cognitive enhancement therapy has also shown to be effective in improving neurocognitive functioning in outpatients with EOS or schizoaffective disorder (Eack et al., 2009). Indeed, family therapy, psycho-education, and social skills training have also shown improvement in clinical symptoms of newly diagnosed patients with schizophrenia (Petersen et al., 2005). A recently published multicenter RCT was conducted on young people with an early initial prodromal state of psychosis, to investigate the effectiveness of integrated psychological intervention (including CBT, group skills training, cognitive remediation therapy, and multifamily psycho-education) and supportive counseling on prevention of psychosis (Bechdolf et al., 2012). The results showed that the integrated psychological intervention was more effective in delaying the onset of psychosis over a 24-month follow-up period (Bechdolf et al., 2012). These studies suggest that psychotherapeutic interventions may thus be an important platform to alleviate psychotic relapse, re-admission, and medication compliance; systematic validation of such measures however is warranted.

\section{CONCLUSION AND FUTURE DIRECTIONS}

Early onset schizophrenia is a rare, severe, and treatmentrefractory form of the adult-onset illness. Although antipsychotic treatment, in addition to psychotherapeutic interventions, provides some symptom relief, there are a very high percentage of residual psychotic symptoms and cognitive deficits. Existing

\section{REFERENCES}

Asarnow, J. R., Tompson, M. C., and Goldstein, M. J. (1994). Childhood-onset schizophrenia: a followup study. Schizophr. Bull. 20, 599-617.

Banaschewski, T., and Brandeis, D. (2007). Annotation: what electrical brain activity tells us about brain function that other techniques cannot tell us - a child psychiatric perspective. J. Child Psychol. Psychiatry 48, 415-435.

Bechdolf, A., Wagner, M., Ruhrmann, S., Harrigan, S., Putzfeld, V., Pukrop, R., Brockhaus-Dumke, A., Berning, J., Janssen, B., Decker, P., Bottlender, R., Maurer, K., Möller, H. J., Gaebel, W., Häfner, H., Maier, W., and
Klosterkötter, J. (2012). Preventing progression to first-episode psychosis in early initial prodoromal states. Br. J. Psychiatry 200, 22-29.

Brewer, W. J., Wood, S. J., Phillips, L. J., Francey, S. M., Pantelis, C., Yung, A. R., Cornblatt, B., and McGorry, P. D. (2006). Generalized and specific cognitive performance in clinical high-risk cohorts: a review highlighting potential vulnerability markers for psychosis. Schizophr. Bull. 32, 538-555.

Brookes, M. J., Woolrich, M., Luckhoo, H., Price, D., Hale, J. R., Stephenson, M. C., Barnes, G. ris, P. G. (2011). Investigating R., Smith, S. M., and Mor-

medication treatments do not result in adequate response and the side effects in children remain daunting. Hence, there is a dire need for early characterization of symptoms and biomarkers, better understanding of the pathophysiology and progression of the illness, and exploring novel and "outside the box" treatment options such as transcranial magnetic stimulation (TMS; Tanaka and Watanabe, 2009), or transcranial direct current stimulation (tDCS) trials, which are well tolerated in pediatric populations (Mattai et al., 2011; Vercammen et al., 2011). Non-invasive neurostimulation techniques such as these have been shown to ameliorate cognition and negative symptoms in schizophrenia (Levkovitz et al., 2011; Minzenberg and Carter, 2012), features commonly reported in early onset cases (Vyas et al., 2011a). However, new treatment strategies should be informed by advancing knowledge from neurochemical and neuroanatomic studies, which may provide more specific targets in the brain. Recent advances in neuroimaging methodologies, particularly those that provide a window into brain functioning and circuitry, may provide a blueprint for identification of novel biomarkers for schizophrenia. For instance, resting-state and task orientated functional MRI or magnetoencephalography (MEG) analyses show abnormal brain synchrony and neural networks in schizophrenia (Reite et al., 1999; Banaschewski and Brandeis, 2007; Ford et al., 2007; Brookes et al., 2011; Ikezawa et al., 2011). An ongoing MEG study from our NIMH COS cohort showed abnormal oscillatory patterns in COS patients compared to healthy controls (N. S. Vyas, unpublished data). Treatment strategies could be ideally designed (e.g., regionally specific neuromodulation using tDCS) to "normalize" these abnormal brain circuitries or evaluate efficacy of new compounds. Research and implementation of novel treatments coupled with advances in genome-wide microarray technology may lead to the identification of genes that are relevant not only in the pathophysiology of schizophrenia, but also in providing an insight into treatment response, or course prediction.

\section{ACKNOWLEDGMENTS}

Dr. Nora S. Vyas is supported by the Fulbright Distinguished Scholar Award by the US-UK Fulbright Commission, and more recently the Lindemann Trust fellowship of the English-Speaking Union.

the electrophysiological basis of resting state networks using magnetoencephalography. Proc. Natl. Acad. Sci. U.S.A. 108, 16783-16788.

Cadenhead, K. S., Addington, J., Cannon, T., Cornblatt, B., McGlashan, T., Perkins, D., Seidman, L., Tsuang, M., Walker, E., Woods, S., and Heinssen, R. (2010). Treatment history in the psychosis prodrome: characteristics of the North American Prodrome Longitudinal Study Cohort. Early Interv. Psychiatry 4, 220-226.

Cannon, T. D., Cadenhead, K., Cornblatt, B., Woods, S. W., Addington, J., Walker, E., Seidman, L. J., Perkins, D., Tsuang, M., McGlashan,
T., and Heinssen, R. (2008). Prediction of psychosis in youth at high clinical risk: a multisite longitudinal study in North America. Arch. Gen. Psychiatry 65, 28-37.

Caplan, R. (1994). Communication deficits in childhood schizophrenia spectrum disorders. Schizophr. Bull. 20, 671-683.

Childs, B., and Scriver, C. R. (1986). Age at onset and causes of disease. Perspect. Biol. Med. 29, 437-460.

Connor, D. F., Fletcher, K. E., and Wood, J. S. (2001). Neuroleptic-related dyskinesias in children and adolescents. J. Clin. Psychiatry 62, 967-974. 
Eack, S. M., Greenwald, D. P., Hogarty, S. S, Cooley, S. J., DiBarry, A. L., Montrose, D. M., and Keshaven, M. S. (2009). Cognitive enhancement therapy for early course schizophrenia: effects of a two-year randomized controlled trial. Psychiatr. Serv. 60, 1468-1476.

Findling, R. L., Schulz, S. C., Reed, A. D., and Blumer, J. L. (1998). The antipsychotics: a pediatric perspective. Pediatr. Clin. North Am. 45, 1205-1232.

Fleischhaker, C., Schulz, E., Tepper, K., Martin, M., Hennighausen, K., and Remschmidt, H. (2005). Long-term course of adolescent schizophrenia. Schizophr. Bull. 31, 769-780.

Ford, J. M., Krystal, J. H., and Mathalon, D. H. (2007). Neural synchrony in schizophrenia: from networks to new treatment. Schizophr. Bull. 33, 848-852.

Gogtay, N., and Rapoport, J. (2008). Clozapine use in children and adolescents. Expert Opin. Pharmacother. 9, 459-465.

Gogtay, N., Sporn, A., Clasen, L. S., Greenstein, D., Giedd, J. N., Lenane, M., Gochman, P. A., Zijdenbos, A., and Rapoport, J. L. (2003). Structural brain MRI abnormalities in healthy siblings of patients with childhood-onset schizophrenia. Am. J. Psychiatry 160, 569-571.

Gogtay, N., Sporn, A., Clasen, L. S., Nugent, T. F. III, Greenstein, D., Nicolson, R., Giedd, J. N., Lenane, M., Gochman, P., Evans, A., and Rapoport, J. L. (2004). Comparison of progressive cortical gray matter loss in childhood-onset schizophrenia with that in childhoodonset atypical psychoses. Arch. Gen. Psychiatry 61, 17-22.

Gogtay, N., Vyas, N. S., Testa, R., Wood, S. J., and Pantelis, C. (2011). Age of onset of schizophrenia: perspectives from structural neuroimaging studies. Schizophr. Bull. 37, 504-513.

Gornick, M. C., Addington, A. M., Sporn, A., Gogtay, N., Greenstein, D., Lenane, M., Gochman, P., Ordonez, A., Balkissoon, R., Vakkalanka, R., Weinberger, D. R., Rapoport, J. L., and Straub, R E. (2005). Dysbindin (DTNBP1, 6p22.3) is associated with childhood-onset psychosis and endophenotypes measured by the Premorbid Adjustment Scale (PAS). J. Autism Dev. Disord. 35, 831-838.

Greenstein, D., Lenroot, R., Clausen, L., Chavez, A., Vaituzis, A. C., Tran, L., Gogtay, N., and Rapoport, J. L. (2011). Cerebellar development in childhood onset schizophrenia and non-psychotic siblings. Psychiatry Res. 193, 131-137.

Gross, G., Huber, G., Klosterkotter, J., and Linz, M. (1987). Bonner Skalar fur die Beurteilung von BasisSymptomen. Berlin: Springer, 1995.

Heaton, R. K., Gladsjo, J. A., Palmer, B. W., Kuck, J., Marcotte, T. D., and Jeste, D. V. (2001). Stability and course of neuropsychological deficits in schizophrenia. Arch. Gen. Psychiatry 58, 24-32.

Heinrichs, R. W., and Zakzanis, K. K. (1998). Neurocognitive deficit in schizophrenia: a quantitative review of the evidence. Neuropsychology 12, 426-445.

Hollis, C. (2000). Adult outcomes of child- and adolescent-onset schizophrenia: diagnostic stability and predictive validity. Am. J. Psychiatry 157, 1652-1659.

Ikezawa, K., Ishii, R., Iwase, M., Kurimoto, R., Canuet, L., Takahashi, H., Nakahachi, T., Azechi, M., Ohi, K., Fukumoto, M., Yasuda, Y., Iike, N., Takaya, M., Yamamori, H., Kazui, H., Hashimoto, R., Yoshimine, T., and Takeda, M. (2011). Decreased alpha event-related synchronization in the left posterior temporal cortex in schizophrenia: a magnetoencephalographybeamformer study. Neurosci. Res. 71, 235-243.

Jacobsen, I. K., and Rapoport, J. L. (1998). Childhood-onset schizophrenia: rare but worth studying. Biol. Psychiatry 46, 1418-1428.

Javitt, D. C., Spencer, K. M., Thaker, G. K., Winterer, G., and Hajós, M. (2008). Neurophysiological biomarkers for drug development in schizophrenia. Nat. Rev. Drug Discov. 7, 68-83.

Keefe, R. S. E., and Fenton, W. S. (2007). How should DSM-V criteria for schizophrenia include cognitive impairment? Schizophr. Bull.33, 912-920.

Kennedy, E., Kumar, A., and Datta, S. S. (2007). Antipsychotic medication for childhood-onset schizophrenia. Cochrane Database Syst. Rev. 4, $1-44$.

Kumra, S., Frazier, J. A., Jacobsen, L. K., McKenna, K., Gordon, C. T., Lenane, M. C., Hamburger, S. D., Smith, A. K., Albus, K. E., AlaghbandRad, J., and Rapoport, J. L. (1996). Childhood-onset schizophrenia. A double-blind clozapine-haloperidol comparison. Arch. Gen. Psychiatry 53, 1090-1097.

Kumra, S., Kranzler, H., Gerbino-Rosen, G., Kester, H. M., De Thomas, C., Kafantaris, V., Correll, C. U., and Kane, J. M. (2008). Clozapine and 'high-dose' olanzapine in refractory early-onset schizophrenia: a 12-week randomized and doubleblind comparison. Biol. Psychiatry 63, 524-529.

Levkovitz, Y., Rabany, L., Harel, E. V., and Zangen, A. (2011). Deep transcranial magnetic stimulation add-on for treatment of negative symptoms and cognitive deficits of schizophrenia: a feasibility study. Int. J. Neuropsychopharmacol. 14 991-996.

Madaan, V., Dvir, Y., and Wilson, D. R. (2008). Child and adolescent schizophrenia: pharmacological approaches. Expert Opin. Pharmacother. 9, 2053-2068.

Masi, G., and Liboni, F. (2011). Management of schizophrenia in children and adolescents: focus on pharmacotherapy. Drugs 71, 179-208.

Mattai, A., Miller, R., Weisinger, B., Greenstein, D., Bakalar, J., Tossell, J., David, C., Wassermann, E. M., Rapoport, J., and Gogtay, N. (2011). Tolerability of transcranial direct current stimulation in childhoodonset schizophrenia. Brain Stimul. 4, 275-280.

McClellan, J., Breiger, D., McCurry, C., and Hlastala, S. (2003). Premorbid functioning in early-onset psychotic disorders. J. Am. Acad. Child Adolesc. Psychiatry 42, 666-672.

McClellan, J., and Werry, J. (2001). Practice parameter for the assessment and treatment of children and adolescents with schizophrenia. J. Am. Acad. Child Adolesc. Psychiatry 40, 4S-23S.

McEvoy, J. P., Lieberman, J. A., Stroup, T. S., Davis, S. M., Meltzer, H. Y., Rosenheck, R. A., Swartz, M. S., Perkins, D. O., Keefe, R. S., Davis, C. E., Severe, J., and Hsiao, J. K. (2006). Effectiveness of clozapine versus olanzapine, quetiapine, and risperidone in patients with chronic schizophrenia who did not respond to prior atypical antipsychotic treatment. Am. J. Psychiatry 153, 600-610.

McGlashan, T. H., Miller, T. J., Woods, S. W., Hoffman, R. E., and Davidson, L. (2001). "A scale for the assessment of prodromal symptoms and states," in Early Intervention in Psychotic Disorders, eds T. J. Miller, S. A. Menick, T. H. McGlashan, J. Liberger, and J. O. Jahannessen (Dordrecht: Kluwer Academic Publishers), 135-149.

McGorry, P. D., Yung, A., and Phillips, L. (2001). Ethics and early intervention in psychosis: keeping up the pace and staying in step. Schizophr. Res. 51, 17-29.
McGorry, P. D., and Killackey, E. J. (2002). Early intervention in psychosis: a new evidence based paradigm. Epidemiol. Psichiatr. Soc. 11, 237-247.

McGurk, S. R., Twamley, E. W., Sitzer, D. I., McHugo, G. J., and Mueser, K. T. (2007). A meta-analysis of cognitive remediation in schizophrenia. Am. J. Psychiatry 164, 1791-1802.

Micó, J. A., Rojas-Corrales, M. O., Gibert-Rahola, J., Parellada, M., Moreno, D., Fraguas, D., Graell, M. Gil, J., Irazusta, J., Castro-Fornieles, J., Soutullo, C., Arango, C., Otero, S., Navarro, A., Baeza, I., MartínezCengotitabengoa, M., and GonzálezPinto, A. (2011). Reduced antioxidant defense in early onset firstepisode psychosis: a case-control study. BMC Psychiatry 11, 26. doi:10.1186/1471-244X-11-26

Miller, T. J., McGlashan, T. H., Woods, S. W., Stein, K., Driesen, N., Corcoran, C. M., Hoffman, R., and Davidson, L. (1999). Symptom assessment in schizophrenic prodromal states. Psychiatr. Q. 70, 273-287.

Minzenberg, M. J., and Carter, C. S. (2012). Developing treatments for impaired cognition in schizophrenia. Trends Cogn. Sci. (Regul. Ed.) 16, 35-62.

Mozes, T., Toren, P., Chernauzan, N., Mester, R., Yoran-Hegesh, R., Blumensohn, R., and Weizman, A. (1994). Clozapine treatment in very early onset schizophrenia. J. Am Acad. Child Adolesc. Psychiatry 33, 65-70.

Nicolson, R., Lenane, M., Singaracharlu, S., Malaspina, D., Giedd, J. N., Hamburger, S. D., Gochman, P., Bedwell, J., Thaker, G. K., Fernandez, T., Wudarsky, M., Hommer, D. W., and Rapoport, J. L. (2000). Premorbid speech and language impairments in childhood-onset schizophrenia: association with risk factors. Am. J. Psychiatry 157, 794-800.

Nicolson, R., and Rapoport, J. L. (1999). Childhood-onset schizophrenia: rare but worth studying. Biol. Psychiatry 46, 1418-1428.

Pantelis, C., Velakoulis, D., McGorry, P. D., Wood, S. J., Suckling, J., Phillips, L. J., Yung, A. R., Bullmore, E. T., Brewer, W., Soulsby, B., Desmond, P., and McGuire, P. K. (2003). Neuroanatomical abnormalities before and after onset of psychosis: a cross-sectional and longitudinal MRI comparison. Lancet 361, 281-288.

Patterson, T. L., and Leewenkamp, O. R. (2008). Adjunctive psychosocial therapies for the treatment of 
schizophrenia. Schizophr. Res. 100, 108-119.

Petersen, L., Jeppesen, P., Thorup, A., Abel, M. B., Øhlenschlaeger, J., Christensen, T. Ø., Krarup, G., Jørgensen, P., and Nordentofy, M. (2005). A randomized multicentre trial of integrated versus standard treatment for patients with a first episode of psychotic illness. BMJ 331,602 .

Phillips, L. J., Young, A. R., and McGorry, P. D. (2002). Identification of young people at risk of psychosis: validation of Personal Assessment and Crisis Evaluation Clinic intake criteria. Aust. N. Z. J. Psychiatry 34(Suppl.), S164-S169.

Pool, D., Bloom, W., Mielke, D. H., Roniger, J. J. Jr., and Gallant, G. M. (1976). A controlled evaluation of loxitane in seventy-five adolescent schizophrenic patients. Curr. Ther. Res. Clin. Exp. 19, 99-104.

Rapoport, J. L., Giedd, J., Kumra, S., Jacobsen, L., Smith, A., Lee, P., Nelson, J., and Hamburger, S. (1997). Childhood-onset schizophrenia. Progressive ventricular change during adolescence. Arch. Gen. Psychiatry 54, 897-903.

Rapoport, J. L., and Gogtay, N. (2011). Childhood onset schizophrenia: support for a progressive neurodevelopmental disorder. Int. J. Dev. Neurosci. 29, 251-258.

Realmuto, G. M., Erickson, W. D., Yellin, A. M., Hopwood, J. H., and Greenberg, L. M. (1984). Clinical comparison of thiothixene and thioridazine in schizophrenic adolescents. Am. J. Psychiatry 141, 440-442.

Reite, M., Teale, P., and Rojas, D. C. (1999). Magnetoencephalography: applications in psychiatry. Biol. Psychiatry 45, 1553-1563.

Ruhrmann, S., Schultze-LutterRaimo, F., Salokangas, R. K. R., Heinimaa, M., Linszen, D., Dingemans, P., Birchwood, M., Patterson, P.,
Juckel, G., Heinz, A., Morrison, A., Lewis, S., von Reventlow, H. G., and Klosterkötter, J. (2010). Prediction of psychosis in adolescents and young adults at high risk: results from the prospective European Prediction of Psychosis study. Arch. Gen. Psychiatry 67, 241-251.

Sikich, L., Frazier, J. A., McClellan, J., Findling, R. L., Vitiello, B., Ritz, L., Ambler, D., Puglia, M., Maloney, A. E., Michael, E., De Jong, S., Slifka, K., Noyes, N., Hlastala, S., Pierson, L., McNamara, N. K., Delporto-Bedoya, D., Anderson, R., Hamer, R. M., and Lieberman, J. A. (2008). Double-blind comparison of first- and second-generation antipsychotics in early-onset schizophrenia and schizo-affective disorder: findings from the treatment of early-onset schizophrenia spectrum disorders (TEOSS) study. Am. J. Psychiatry 165, 1420-1431.

Spencer, E. K., Kafantaris, V., PadronGayol, M. V., Rosenberg, C. R., and Campbell, M. (1992). Haloperidol in schizophrenic children: early findings from a study in progress. Psychopharmacol. Bull. 28, 183-186.

Sporn, A. L., Vermani, A., Greenstein, D. K., Bobb, A. J., Spencer, E. P., Clasen, L. S., Tossell, J. W., Stayer, C. C., Gochman, P. A., Lenane, M. C., Rapoport, J. L., and Gogtay, N. (2007). Clozapine treatment of childhood-onset schizophrenia: evaluation of effectiveness, adverse effects, and long-term outcome. J. Am. Acad. Child Adolesc. Psychiatry 46, 1349-1356.

Tanaka, S., and Watanabe, K. (2009). Transcranial direct current stimulation: a new tool for human cognitive neuroscience. Brain Nerve 61, 53-64.

Taurines, R., Thome, J., Duvigneau, J. C., Forbes-Robertson, S., Yang, L., Klampfl, K., Romanos, J., Müller, S., Gerlach, M., and Mehler-Wex, C. (2010). Expression analyses of the mitochondrial complex I 75-kDa subunit in early onset schizophrenia and autism spectrum disorder: increased levels as a potential biomarker for early onset schizophrenia. Eur. Child. Adolesc. Psychiatry 19, 441-448.

Towbin, K. E., Dykens, E. M., and Pugliese, R. G. (1994). Clozapine for early developmental delays in childhood-onset schizophrenia: protocol and 15-month outcome. J. Am. Acad. Child. Adolesc. Psychiatry 33, 651-657.

Vercammen, A., Rushby, J. A., Loo, C., Short, B., Weickert, C. S., and Weickert, T. W. (2011). Transcranial direct current stimulation influences probabilistic association learning in schizophrenia. Schizophr. Res. 131, 198-205.

Vyas, N. S., Hadjulis, M., Vourdas, A., Byrne, P., and Frangou, S. (2007). The Maudsley early onset schizophrenia study. Predictors of psychosocial outcome at 4-year followup. Eur. Child Adolesc. Psychiatry 12, 465-470.

Vyas, N. S., Kumra, S., and Puri, B. K. (2010). What insights can we gain from studying early-onset schizophrenia? The neurodevelopmental pathway and beyond. Expert Rev. Neurother. 10, 1243-1247.

Vyas, N. S., Patel, N. H., and Puri, B. K. (2011a). Neurobiology and phenotypic expression in early onset schizophrenia. Early Interv. Psychiatry 5 , 3-14.

Vyas, N. S., Patel, N. H., Nijran, K. S., AlNahhas, A., and Puri, B. K. (2011b). The use of PET imaging in studying cognition, genetics and pharmacotherapeutic interventions in schizophrenia. Expert. Rev. Neurother. 11 , 37-51.

Vyas, N. S., Shamsi, S. A., Malhotra, A. K., Aitchison, K. J., and Kumari, V. (2012). Can genetics inform the management of cognitive deficits in schizophrenia? J. Psychopharmacol. 26, 334-348.

Weinberger, D. R. (1987). Implications of normal brain development for the pathogenesis of schizophrenia. Arch. Gen. Psychiatry 44, 660-669.

Wiedemann, K. (2011). Biomarker in development of psychotrophic drugs. Dialogues Clin. Neurosci. 13, 225-234.

Yung, A. R., and McGorry, P. D. (1996). The prodromal phase of first-episode psychosis: past and current conceptualizations. Schizophr. Bull. 22, 353-370.

Yung, A. R., Phillips, L. J., Yuen, H. P., and McGorry, P. D. (2004). Risk factors for psychosis in an ultra highrisk group: psychopathology and clinical features. Schizophr. Res. 67, 131-142.

Conflict of Interest Statement: The authors declare that the research was conducted in the absence of any commercial or financial relationships that could be construed as a potential conflict of interest.

Received: 13 January 2012; accepted: 16 March 2012; published online: 02 April 2012.

Citation: Vyas NS and Gogtay N (2012) Treatment of early onset schizophrenia: recent trends, challenges and future considerations. Front. Psychiatry 3:29. doi: 10.3389/fpsyt.2012.00029

This article was submitted to Frontiers in Child and Neurodevelopmental Psychiatry, a specialty of Frontiers in Psychiatry. Copyright $\odot 2012$ Vyas and Gogtay. This is an open-access article distributed under the terms of the Creative Commons Attribution Non Commercial License, which permits non-commercial use, distribution, and reproduction in other forums, provided the original authors and source are credited. 